\title{
'Emptying the cage, changing the birds': State rescaling, path-dependency and the politics of economic restructuring in post-crisis Guangdong
}

\section{Introduction}

The Pearl River Delta (hereafter PRD) extended metropolitan region in the southeastern corner of China has functioned as the national economic 'motor' since experimentation with global economic (re)integration began in 1978. By official definition, the PRD comprises nine cities, namely Guangzhou, Shenzhen, Zhuhai, Foshan, Huizhou, Dongguan, Zhongshan, Jiangmen, and Zhaoqing. Encompassing less than $1 \%$ of China's total land area and registering less than $4 \%$ of the total national population, the nine mainland cities account for almost $10 \%$ of China's GDP $^{1}$ over the last decade; during the same period, the region embedded an estimated $20 \%$ of its foreign direct investment (FDI) and generated approximately $25 \%$ of national trade. The location of three of China's first four Special Economic Zones (SEZs), namely Shantou, Shenzhen, and Zhuhai, the PRD is part of a broader Guangdong province that absorbed the largest number of domestic migrant workers since cross-country mobility was relaxed in the 1980s (Chinese Population Census, 2010). Viewed as an integrated whole, this city-region has become deeply articulated in the global economy.

The global financial crisis of 2008 made it clear, however, that global economic integration through Guangdong was a double-edged sword. As economic slowdown became apparent in early 2008, the biggest challenge for the-then newly-appointed Party Secretary of Guangdong, Wang Yang, was to ensure decreasing global demand did not transpose into negative economic growth. The Guangdong provincial government subsequently responded with a strategy of state-driven value chain upgrading known as “double relocation" (shuang zhuanyi). Launched in tandem with policies to 'scale up' the national significance of three territories in the PRD (Hengqin, Qianhai and Nansha; ref Figure 1$)^{2}$, “double location” involved shifting labor categorized as 'low-skilled' and firms 
categorized as "high in pollution, high in energy use and low in efficiency" (lianggao yidi) from the PRD to the underdeveloped regions of the province ${ }^{3}$.

Figure 1 here

Problems emerged when this policy appeared to undermine the structural stability of the national political economy. It foregrounds, in turn, two contradictory aspects of the relationship between the Guangdong provincial government and the top echelon of the Communist Party of China (CPC). At one level, the 'double relocation' policy reflects a specific post-Mao "political logic" of reforms known as "reciprocal accountability" (Shirk, 1993). This logic invites developmental initiatives of national significance from local governments, in the anticipation that these governments would reciprocate by aligning their initiatives to national objectives (cf. Rawski, 1995; Sheng, 2010). At another level, however, it challenged the longstanding policymaking philosophy officially termed 'the entire country as a chessboard' (quanguo yipanqi). This emphasis on holistic national governance was first espoused by Ke Qingshi, the former Mayor of Shanghai and CPC Politburo member, in 1959 (Ke, 1959; cf. editorial in People’s Daily, 24 February 1959). While the socioeconomic context of the 1950s differed significantly from that of contemporary China, national-scale regulation in the form of 'macro adjustments' (hongguan tiaokong) continues to underpin central policymaking (cf. Webber et al, 2002; Zhao, 2009). Opposition to the 'double relocation' policy emerged against this backdrop: some senior cadres did not perceive the economic restructuring of Guangdong during and after the 2008 crisis to be a strategic 'move' vis-à-vis the national 'chessboard'.

Drawing from empirical research ${ }^{4}$ conducted on industrial upgrading and policy experimentation in the PRD, this paper conceptualizes the 'double relocation' industrial policy in Guangdong as an expression of the tension between state rescaling and institutional path-dependency. State rescaling refers to the reconfiguration of regulatory relations between the national, subnational and supranational governments, such that what 
represents the 'national interest' is no longer expressed and realized at one scale (i.e. initiated by the central government across the entire state spatiality). Following Peck (2002), Brenner (2004) and Jessop and Sum (2006), this reconfiguration is viewed simultaneously as a medium and an outcome of political strategies launched at different regulatory scales - i.e. the subnational, national and global - vis-à-vis the imperatives of capital accumulation. While rescaling has been accommodated within the Chinese partystate apparatus to facilitate more flexible responses to global economic changes, the paper shows how it potentially destabilizes the coherence of a national politico-economic structure that was (and remains) export-oriented. This is because the process intrinsically contains what Wedeman (2001) terms "strategic disobedience" by actors positioned at lower levels of the administrative hierarchy.

Strategic disobedience becomes possible - if not implicitly encouraged - because guidelines to determine either willful non-conformity or political incompetence are relatively flexible within the party-state structure. Perhaps the most "strategic" aspect of this "disobedience" is the paradoxical attempt by the Guangdong government to justify statedriven industrial upgrading in the name of enhancing national economic development when it 1) goes precisely against the 'national chessboard' pathway instituted since the late 1950s and simultaneously 2) undermines the newer industrialization pathway along the eastern seaboard instituted during the $7^{\text {th }}$ Five-Year Plan (1986-1990). In this regard, the Wang administration's attempt to territorially reconfigure Guangdong's industrial composition - and, by extension, regulatory relations between the central, provincial and city governments - more accurately reflects tensions with national-level spatial strategies launched by earlier regimes. This highlights, in turn, the necessity for a robust historical engagement in conceptualizing Chinese state rescaling.

The paper is organized in four parts. Section 2 situates the emergence of the Chinese political economy as an 'interscalar rule regime' within the framework of state 
rescaling, strategic disobedience and institutional path-dependency. This integrated framework fleshes out two constitutive aspects of state rescaling that remain underfocused in research on Chinese state rescaling - political agency and historical contingency. Section 3 will explain how a rolling series of national-level spatial strategies came in tension with the 'double relocation' industrial policy. Building on this geographicalhistorical basis, section 4 shows how simultaneous industrial relocation and value chain upgrading was portrayed as an impossible task vis-à-vis the prevailing export-driven and coastal-based approach to capital accumulation. It was for this reason that economic restructuring in Guangdong became politicized at the national scale. The concluding section emphasizes how state rescaling in Guangdong was contingent on industrial reconfigurations that were never ascertained a priori by the Chinese central government. Conceptually, this phenomenon raises the question whether state rescaling is an ad hoc process for local governments in China to perpetuate the narrowly-defined developmental approach known as 'GDP-ism', or, perhaps counter-intuitively, whether it has become a function of central governance across the Chinese political economy.

\section{State rescaling, path-dependency and economic restructuring in post-Mao China}

The concept of state rescaling was originally developed to understand the transformation of Fordist-Keynesianism, namely the structurally-coherent model of 'mass production, mass consumption' that underpinned national-scale development in western Europe after WWII. As this coherence destabilized from the mid-1970s, proactive spatial strategies are observed to have led to the re-articulation of (nationally-oriented) political economies within the global system of capitalism (Peck, 2002, 2003; Brenner, 2004, 2009; Jones and Jessop, 2010). This shift was primarily characterized by the growing concentration of developmental resources in city-regions in western Europe. Correspondingly, there was a 
rollback in the relatively egalitarian distribution of economic opportunities across the national territories.

State rescaling was and remains reactive to the crisis tendencies of capitalism in the first instance. Scalar reconfiguration was necessary because earlier strategies that emphasized national-scale regulation in the Fordist heartlands simultaneously generated constraints on the ability of firms to sustain growing rates of profits (Lipietz, 1982; 1997). The ensuing crisis of Fordism led Brenner (2004) to hypothesize in New State Spaces (2004), a major book-length reference point to state rescaling, that "urbanization processes would engender contextually specific forms of sociospatial dislocation and crisis formation, as well as corresponding strategies of political intervention designed to confront the latter." (Brenner, 2009: 127). What the rescaling process characterizes, then, is a rolling transformation with no end-state (cf. Peck, 2003); it is, more precisely, an intensifying and recursive response to the socioeconomic instability intrinsic to capital accumulation. Driving this process are new interventionist policies in targeted territories. As Brenner (2009b: 128) explains,

since the 1990s, new forms of state rescaling have emerged largely in response to the crisis tendencies engendered through the first wave of urban locational policy. This has led to the construction of new scales of state intervention (neighbourhoods, metropolitan regions and transnational interurban networks), to the crystallization of additional crisis tendencies and dislocations and, subsequently, to a further intensification and acceleration of rescaling processes. Processes of state rescaling therefore appear to be animated through regulatory failure.

Primary aspects of "regulatory failure" in western Europe were encapsulated within the dismantlement of what Jessop (1993) terms 'Keynesian welfare state". These aspects were the weakening welfarist state system; the 'internationalization' of previously-Fordist corporations; and the "hollowing out" of the state (cf. Rhodes, 1997; Peck, 2001). For Jessop and Sum (2006: 271, 281), the decline of the national scale as the "taken-forgranted object of economic management" across Atlantic Fordism, the East Asian 'trading nations' and important-substituting Latin America marked the emergence of a 
"relativisation of scale" in socioeconomic regulation, namely "the absence of a dominant nodal point in managing interscalar relations".

A major expression of this "relativisation" is the emergence of inter-scalar rule regimes. These regimes are produced when central state institutions, "reconceived and restructured" under pressures from/of (neoliberalizing) globalization, increasingly engage "in more active processes of scale management and coordination at the local and international levels" (Peck, 2002: 340). The devolution and outsourcing of central control in this new state form is expressed in the growing importance of subnational 'rule regimes' with new politics and socioeconomic policies that involve and impact actors positioned in different scales - in relation to national and supranational regulatory bodies (Peck, 2002; Harrison, 2012; Jonas, 2013). Inter-scalar rule regimes presuppose the function of national political economies as dynamic platforms that shape and are shaped by intrinsically speculative policy experimentation in targeted locations. Their emergence foregrounds tensions between attempts to re-define the preexisting regulatory structure of state space through new policy initiatives and attempts to retain and/or repurpose this structure. An important empirical question for research on inter-scalar rule regimes is whether these tensions could be resolved and/or deferred in order to facilitate sustained capital accumulation.

Certain distinctions must be made when ascertaining the relevance of this question in the socioeconomic context of post-Mao China. The spatial logics of socioeconomic regulation during the Mao Zedong era (1949-1976) was never predicated on a Fordist mode of production and its corresponding state form, the Keynesian welfare state. Rather, the Mao administration sought to negate urbanizing impulses through systematic controls of demographic and resource flows. The scalar regulatory template was characterized by three interrelated arrangements. First, approximately $80 \%$ of the population was segregated from cities through the urban-rural 'dual structure' (chengxiang eryuan jiegou). 
Second, residents within the rural hinterland were divided into production units known as the 'People's Communes'. Third, centrally-directed industrial production was based predominantly in cities, while raw materials were supplied through administrativelydecentralized rural communes. Integration with the global economy was minimal. The primary "regulatory failure" during this period was the inability of economically nationalistic policies to raise living standards and reduce poverty for the majority of the population. With Mao's passing in 1976, the CPC urgently needed to overcome this problem. A major recourse was to re-integrate city-regions with the global system of capitalism, and as section 3 will elaborate, this would first take place in Guangdong.

Research has demonstrated how the gradual but ultimately expansionary exposure of Chinese state space to transnational processes of production and consumption has triggered the urbanization of capital and labor power (Ma, 2005; Shen, 2007; He and Wu, 2009). This shift was neither a sudden effect of market-oriented reforms nor firm-induced relocations due to falling profit rates. As Ma (2005: 483) puts it, CPC cadres had been keen to expand development even during the Mao era: "Despite Mao's personal antiurbanism during the Cultural Revolution (1966-1976), the urban scale has always been the preferred scale on the part of officials." This preference was shaped, in turn, by industrial developments in pre-1949 'old society'. At the time, industrial capital goods were heavily concentrated along coastal cities as well as the Japanese-controlled northeast (then known as Manchukuo). After the Deng Xiaoping government launched SEZs in 1980 and expanded these zones to other cities in 1984, an increasingly urbanizing inter-scalar rule regime emerged (Cartier, 2005; Huang, 2008; He and Wu, 2009; Wu, 2015). Ma (2005: 495) reflects on the implications of this new development:

From the perspective of scale relations, China's focus on the national scale of development during the socialist era has been replaced by a downward shift in the scale of operation focused on the cities. With such a shift, the earlier preeminent and monopolistic state mode of articulation has been rescaled downward to the urban scale. This development raises the question as to what roles should subnational scales, i.e., provincial, regional, county and 
township, play in national development and what should their scalar relations be. (Ma, 2005: 495)

The primary question to be asked of this new rule regime is the relationship between urban-based industrial development and the enhancement of the 'national interest'. It remains unclear, specifically, how the urban scale could constitute the "national strategy" of development within the context of a Leninist party-state apparatus. Perhaps more crucially, the relationship between Mao-era institutional legacies and the growing urbanization of capital (including labor power) remains an open empirical question. To address this, the paper will consider the role of institutional path-dependency in the process of state rescaling.

Arguably the most common definition of path dependence is the constitutive - if not also constraining - influence of previous actions or decisions on current and future actions/decisions. As Page (2006: 89) puts it, path dependence "requires a build-up of behavioral routines, social connections, or cognitive structures around an institution." Central to this process is the eventual formation of institutional "lock in", in which a practice or policy becomes effective or feasible because a large number of people have adopted or become used to this practice or policy. Even if the available alternatives were inherently superior to the existing institutional practices, any drastic alterations to the path would naturally encounter resistance ${ }^{5}$ from groups of 'locked in' actors because the proposed changes would compromise their interests. It is important to note, however, that the "build up" to specific pathways is often overlooked (Page, 2006). Path formation is commonly construed as an accidental outcome, but this is not necessarily the case. In a thorough review, Peters et al (2005) identify a tendency in research on institutional path-dependence to accord history a logical trajectory, or "retrospective rationality", such that available alternatives and political conflicts that occurred in tandem with the actual occurrences of historical processes are neglected. As such, argue Peter et al (2005: 1282), "prediction of 
persistence does not help at all in understanding institutional change."

The notion of a "logical trajectory" is further complicated because developmental pathways are geographically variegated. As Martin and Sunley (2006) and Martin (2010) have shown, the developmental paths of subnational regions are neither unique nor delimited to those regions. These interventions foreground two interrelated blind spots in the historical institutionalist literature on path-dependency: the socio-spatial context in and through which a specific 'path' was set is often unclear, as is the connection between changes at the subnational or supranational scales and the structural coherence of the national political economy. Through an emphasis on state rescaling as a politicized process, this paper will demonstrate institutional path-dependency as an open-ended, inter-scalar process. Attempts at breaking out of subnational paths through regulatory reconfigurations need not generate new paths at the national scale; on the contrary, they could potentially reinforce the "persistence" and "locked in" status quo of these paths.

The emphasis on political agency in this paper is deliberate. Across China, subnational development is driven by a diverse and often overlapping array of interest groups (cf. Horowitz and Marsh, 2002; Breslin, 2007; Sheng, 2007). They range from local governments (e.g. provincial, county and/or urban governments) seeking to bolster GDP growth rates (Yu, 2014a; $\mathrm{Wu}, 2015)$; village collectives seeking rent from leasing land for non-agricultural activities (Zheng et al, 2009; Wang et al, 2009); state-owned enterprises (SOEs) seeking to enhance their positions at the national scale through local market capture (Bai et al, 2004; Yu, 2014b); third-party associations lobbying for better operating conditions for their members (Pearson, 1994; Chen, 2003; Deng and Kennedy, 2010); and, last but not least, TNCs seeking locations that offer the best opportunities for 'strategic coupling' (Demurger et al, 2002; Wei and Liao, 2013).

The primary goal of these interest groups is to secure fresh opportunities for capital accumulation; the challenge for the central government is to align this goal to the eventual 
formation of a 'socialist market economy'. To do so successfully in the context of growing economic openness entails seeking out new regulatory spaces within which preferential policies can be implemented without destabilizing the legacies of inherited institutions (cf. Solinger, 2005). This delicate balancing act reflects an undercurrent of state rescaling possibly unique to China: it is made possible by 1) the central government's experimental and gradualist approach to instituting new policies (Naughton, 1995; Göbel, 2011; Heilmann and Perry, 2011) and 2) the national system of reciprocal accountability that entails both central and local decisions to complement those of other levels (Shirk, 1993; Naughton, 2008; Xu, 2011).

The willingness of senior CPC policymakers to listen to local-level proposals reinforces the importance of "reciprocal accountability" in two aspects. One, the growing exposure of Chinese state spatiality to transnational capital flows calls for flexible and geographically-specific responses to opportunities that could not be predetermined at/for the national scale. Two, because of the need for the central government to be flexible in generating place-specific responses to opportunities or problems generated by transnational economic integration, there is no one-size-fits-all national developmental agenda. In response to these open-ended aspects, local governments have been lobbying national agencies such as the National Development and Reform Commission (NDRC), the People's Bank of China $(\mathrm{PBoC})$ and the State Administration of Foreign Exchange (SAFE) to implement experimental policies in their jurisdictions that contribute to the 'national strategy' (guojia zhanlüe). The rationale of state rescaling is therefore as likely to be motivated by the political agendas of these local governments as they are aligned to national objectives.

To follow Wedeman $(2001,2003)$, local governments' enthusiasm for reforms and policy experimentation could transpose into a form of "disobedience". In China's long and entrenched hierarchical chain of command, Wedeman (2001: 71) argues, "structurally 
induced ambiguities create opportunities [for cadres] to engage in willful disobedience because they imply that willful disobedience will go unpunished". And in the context of Guangdong politico-economic development, this "disobedience" is exemplified by a wellknown 'traffic light theory' (denglun): "when the red light flashes, detours are made; when the yellow light flashes, there is a mad dash; when the green light flashes, everyone clamors to move". As the discussion will show, however, Wedeman's (2001) postulation has two limiting assumptions. First, he assumed a directive from the Chinese central government - the metaphorical traffic light - had to be issued prior to any "disobedience". Second, Wedeman took the central government as a unitary unit. Disobedience was therefore a function of and a response to directives from an ostensibly united central government.

These assumptions have to be re-evaluated, however, in light of the intrinsic dynamism of state rescaling. As previously mentioned, the reconfiguration of regulatory relations need not be driven or mandated by national-level institutions in the first instance. Any apparent "disobedience" in the form of reform-minded initiatives is therefore not a direct form of "non-compliance" to a central governmental directive. The policymaking regime in Beijing was never a unitary entity to begin with; any consensus forged would only be temporary and are subject to regular challenges (Lü, 2000; McGregor, 2012; Ferchen, 2013). While various forms of decentralized governance characterized the politicoeconomic evolution of post-1949 'new China', the regulatory rationale in the Mao-era was to keep each province (and the respective administrative scales within each province) separate and directly under the control of the central government (Donnithorne, 1972; Harding, 1981). Even though this regulatory logic still underpins inter-provincial relations in the post-Mao 'transition' to market-like rule, the provincial and municipal governments have been granted greater agency in putting forth developmental agendas in the name of the 'national interest'. What this translates in practical terms is an enhanced - albeit temporary 
- positioning in relation to the global competition for capital. This is the primary reason provincial and municipal officials covet the power to 'move first, experiment first' (xianxing xianshi quan).

Crucially, this competitive dynamic increases at once the power of the provincial and central governments. Within each provincial-level government, each administrative leader has to convince the Party Secretary and Governor of his/her jurisdiction's ability to be the next "nationally strategic" reform frontier; this adds further dynamism to the relations between the provincial and the county/municipal governments. The same logic applies to central-provincial relations. Decentralized governance has taken on the effect of enhancing the legitimacy and power of the central government against a globally interconnected context, an aspect inadequately conceptualized through the centralization-decentralization dichotomy that underpins prevailing research on local resistance. Changing regulatory relations between different levels of governments in China may contain 'disobedience'; indeed, bottom-up initiatives may appear to be bypassing the 'red light' from Beijing, but, as the next two sections will show, neither the process nor the outcome can be understood in zero-sum terms.

\section{Moving out of an established pathway? The emergence of "double relocation" in post-crisis Guangdong}

State rescaling in and through Guangdong during and after the 2008 global financial crisis was inextricably entwined with the evolution and impacts of territorially-targeted reforms implemented earlier at the provincial and national levels. For the large part of the past three decades, Guangdong maintained its leading position in the Chinese economicgeographical hierarchy because of preferential policies instituted during the Deng Xiaoping era ( 1978 to 1992). This position reflects the systemic coastal bias that saw provincial and city governments along the more industrialized eastern seaboard enjoy preferential 
treatment from central government agencies vis-à-vis their counterparts in the lessdeveloped western and northeastern interior. Underpinning Deng Xiaoping's macro-scale approach to spatial reconfiguration was the 'ladder-step transition theory', or tidu tuiyi lilun, first espoused by the Shanghai-based academics Xia Yulong and Feng Zhijun (1982). This prescriptive 'theory' attracted the attention of a senior CPC cadre, Bo Yibo, and subsequently permeated central policymaking circles. It was instituted as a policy blueprint during the $7^{\text {th }}$ Five-Year Plan (1986-1990). Specifically, the blueprint delineated the Chinese political economy into three economic-geographical belts: the eastern (coastal), central, and western. The Deng administration gave one belt (the eastern seaboard) the priority in ascending the development 'ladder'. It assumed that the fruits of development in the 'first mover' belt would diffuse downwards to other rungs of the ladder. The 'ladder step' theory opened up a new geographical template for reforms and simultaneously placated party conservatives through retaining the 'chessboard' approach to national governance (cf. Wang and Hu, 1999; Zhu, 2003; Lin, 2004).

Because of Deng's economic-geographical reconfiguration, Guangdong ranked as China's top province by GDP annually since 1989. Statistics for 2007 - the year before the global financial crisis - indicate that $96 \%$ of import/export trade in Guangdong was concentrated in the PRD. This suggests economic data for Guangdong province would be an effective measure of the economic performance of the PRD (Guangdong Statistical Bureau, 2008). Placed in relation to national-level import/export figures, Guangdong on average accounts for almost $30 \%$ of the national total since China's accession to the WTO in 2001 (National Bureau of Statistics, 2014). Along with the growing inflows of capital, Guangdong province experienced the highest growth in inter-provincial movement of migrant workers - also known widely as the 'floating population' (liudong renkou) - within China between 2000 and 2010 (see full report by Liang et al, 2014). According to the Chinese national population census of 2010, a third of this 'floating population' of around 
200 million was concentrated in Guangdong. A separate national report published in 2014 indicates that Guangdong remained the leading destination: it absorbed $29.4 \%$ of the floating population, which has since increased to 245 million by the end of 2013 (21st Century Business Herald, 11 April 2015). These statistics on trade and employment collectively demonstrate the PRD to be by far the most deeply 'articulated' Chinese cityregion within the global system of capitalism.

This articulation was and remains enabled by the geographical proximity to the post-colonial cities of Hong Kong and Macau. Currently the Special Administrative Regions (SARs) of China, these cities have functioned as offshore capital markets and operating platforms for firms looking to invest in China. What ensued was a cross-border, 'front shop, back factory' spatial division of labor that Lin (1997) terms "red capitalism in south China" (ref. Figure 1). Reflecting the effect of the national-scale 'retain the big and letting go of the small' (zuoda fangxiao) industrial policies, medium and small enterprises have taken the role of manufacturing subcontractors, while the major financiers and lead investors comprise state-owned enterprises (SOEs) and TNCs. The emergence of this multidimensional relationship with foreign capital in and through Guangdong offers an important prism through which to evaluate post-1978 politico-economic reforms in China. Foreign capital investments allowed GDP to grow without the concomitant emergence of a large private capitalist class that is capable of undercutting CPC interests (cf. Dickson, 2008). What 'red capitalism' in Guangdong exemplifies, then, is the ability of the CPC to subsume the enlargement of the non-state economic sector to party goals. Zhang (2013: 1614) puts this state-capital relationship in clear perspective: "the political power of capital in China remains fundamentally embedded in, and interlaced with, the sprawling institutional machinery of the Leninist party-state and the political capacities of the CCP".

The deep(ening) articulation of Guangdong-based enterprises and labor power in global production networks built on and reinforced this relationship. Specifically, it 
generated two developmental pathways that were (and remain) entwined at different scales. At the national level, it was integral to and consolidated Deng Xiaoping's previously mentioned 'ladder step' approach. According to data from the Guangdong Bureau of Statistics (2008), the foreign trade to GDP proportion (also known as the trade dependency ratio $^{6}$ ) for Guangdong province as a whole averaged 150\% per year from 2001 to 2007; the figure for Dongguan, a major manufacturing hub within the PRD, was consistently above $250 \%$ in the same period. By comparison, the national average was (an already-high) $66.2 \%$ in 2007 (National Bureau of Statistics, 2008). At the regional level, it generated technological 'lock in' that thrived on and fed off the national focus on labor-intensive and export-oriented production. Research has demonstrated foreign investments into the Pearl River Delta, particularly those via Hong Kong, did not generate the spillovers that enable industrial upgrading through the 2000s (Huang and Sharif, 2009; Meyer et al, 2012). What ensued, instead, was intra-provincial polarization and a recognition that externally-driven growth was unsustainable (Lu and Wei, 2007; Wei and Liao, 2012). Chen (2007: 193) sums up the constraining effect of this 'lock in':

Most PRD-based firms and factories may be trapped in the assembling and manufacturing segment of the production chain and earning merely labor-processing fees rather than engaged in acquiring technology, developing their own brand-name products, and creating international markets directly.

The regulatory challenge associated with the strong exposure to international trade became pronounced after the 2008 global financial crisis precipitated a sharp decline in effective demand for manufactured goods from Guangdong-based industries. Consequently, the province's total volume of imports and exports decreased for 8 consecutive months from November 2008, with the largest monthly decline rate reaching $31.1 \%$. Foreign capital investments dropped by over $50 \%$. According to customs statistics, the total import/export value in Guangdong recorded 257.87 billion yuan ( US $\$ 40.1$ billion) in the first half of 2009, a 20.7\% decrease year-on-year (People's Daily, 3 August 2009). 
Through an investigation spanning three years, the Nanfang Dushibao (2 April 2012) reported that two waves of factory closures followed after the crisis struck. Between 2008 and 2009, it was estimated that half of the 58,500 Hong Kong-owned export-processing subsidiaries would not survive, while a new wave of closures affecting more sectors took place in 2011. To address this challenge, the newly-installed Wang administration responded swiftly. And this placed the two putatively interrelated pathways on a collision course.

In a candid evaluation published in "The Outline of the Reform and Development Plan for the Pearl River Delta (2008-2020)"7, the Guangdong provincial government delineated how earlier approaches to capital accumulation in the PRD have generated their own internal contradictions:

- The overall industrial body is of the lower-order; value-added of product is not high, the trade structure is not reasonable; innovative capacities are insufficient; and the overall competitiveness is not strong.

- The degree of land development is excessive; the ability to conserve energy and resources is relatively weak; the problems with environmental pollution are relatively pronounced; resource limitations have become apparent; hence the traditional model of development cannot be sustained.

- Urban-rural and regional development remains uneven; the allocation of productive forces is still not reasonable; and the efficiency of spatial usage is not high.

- Social projects are relatively lagging behind; the development of human resources, public service standards and 'soft' cultural capabilities are to be improved.

- The administrative management systems, social management system and other areas continue to face heavy reform tasks; tackling difficulties of reform have become greater.

The Guangdong government responded to these contradictions with a strong dose of 'shock therapy' almost immediately after Wang's appointment in December 2007. The restructuring roadmap was rolled out in March 2008 with four instructions to the local government of Dongguan, Guangdong's major manufacturing hub located between 
Shenzhen and Guangzhou (the provincial capital; ref. Figure 1). These instructions were, namely, to 1) push through the readjustment of the industrial structure and the 'transformation and upgrading' (zhuanxing shengjil) ${ }^{8}$ of commodities produced; 2) reduce the urban population and improve labor force quality; 3) engage in comprehensive planning and gain momentum in the restructuring process; and 4) remain resolute in response to challenges, with a view of dismantling rigid ways of thinking, rigid developmental approaches, and the rigid constellation of interest groups (Guangzhou Daily, 27 March 2008).

Interestingly, these plans preceded the global financial crisis. This strongly suggests industrial reconfiguration in Guangdong was part of a path-changing agenda independent of the crisis. As previously mentioned in section 2, the reconfiguration initiative was local. Its objective was to reshape existing spatial divisions of labor at the provincial scale in order to ensure national economic stability. Read in relation to this objective, the primary goal of the 'Outline' was to enable Guangdong to break out of the centrally established trajectory of export-oriented production. Wang summed up his approach through a strong warning to the Dongguan cadres: "If Dongguan does not reconfigure its industrial structure today, it will be reconfigured by the industrial structure tomorrow" (Ibid.).

By asserting Dongguan would be "reconfigured by the industrial structure tomorrow", Wang demonstrated an awareness that places are vulnerable to capital's inherent tendency to relocate to places that could offer higher rates of profits through cheaper labor costs and/or access to more cost-effective technologies (cf. Massey, 1984; Harvey, 2005). As a major global manufacturing site for TNCs, the PRD was particularly exposed to these pressures. To enable PRD-based firms to generate higher profit rates, Wang played up the importance of place-based agency to preempt the effects of relocation by reconfiguring the industrial structure. This agency is embodied by the ability of local 
governments to influence, proactively and strategically, the course taken by capital. It entails the quick identification of growing economic inefficiencies in firms within their respective jurisdictions. To this end, Wang implored Dongguan's cadres, the "government must fully develop its impact by devising and implementing policies for industrial reconfiguration, transformation and upgrading" (Guangzhou Daily, 27 March 2008; author's translation).

New changes began to unfold rapidly thereafter. In May 2008, less than two months after Wang's visit to Dongguan, the Guangdong government released a provincewide economic restructuring plan known as "Decisions on pushing forth industrial and labor power relocation" (hereafter "Decisions") ${ }^{9}$. Central to the "Decisions" is the economicgeographical strategy of 'double relocation' (shuang zhuanyi). As mentioned in section 1, these 'double relocations' refer to relocating targeted enterprises and the labor power they employ from the PRD to "relocation industrial parks" (chanye zhuanyi gongyeyuan) in the less developed regions of the province, namely the eastern and western ends and the northern highlands (ref. Figure 1). These targeted firms and labor were those generating 'two highs and one low', i.e. high in pollution, high in energy use and low in efficiency (cf. section 1).

Paralleling the relocation process was the strategy to enhance the industrial composition of the PRD through attracting advanced manufacturing and higher-order services. This would be done primarily - though not exclusively - through lobbying the central government to designate the intra-urban territories of Hengqin, Qianhai and Nansha as "nationally strategic" zones of policy experimentation with Macau and Hong Kong. Wang offered a detailed justification of his government's restructuring rationale through the CPC's mouthpiece, People's Daily:

To create an innovative Guangdong model, it is necessary to grasp key domains for autonomous innovation and pivotal sectors and work to overcome the technological barriers that constrain socioeconomic development in Guangdong. While there is a need to enhance 
the innovative tendencies within traditional industries experiencing transformation and upgrading, there is also a need to accelerate the industrialization of innovative technologies; while there is a need to push though new up-and-coming industries, there is also a need to implement technological projects amongst privately-owned sectors, so as to ensure the fruits of innovation are more widely-shared. (Wang Yang, People's Daily 17 October 2008; author's translation)

Labeling the industrial upgrading project 'emptying the cage to change the birds' (tenglong huanniao), Wang emphasized that his aim was to preclude economic 'hollowing out' by encouraging the growth of more high-tech firms:

For the Pearl River Delta, the point is to develop higher-order technologies endogenously, within the productive mechanisms of traditional industries, in turn realizing the true meaning of 'emptying the cage and changing the birds' (tenglong huanniao), or it could be called 'expanding the cage and strengthening the birds' (kuolong zhuangniao). On this basis, the situation of economic 'hollowing out' in the process of industrial transformation and upgrading could also be avoided. (lbid.)

Wang's essay was an explicit attempt to justify the suddenness and ambitious extent of his developmental agenda after its implementation sparked widespread discussion and debate over its political and economic implications. In a Chinese political circle where key actors predominantly deploy codified language 'internal to the institution' (tizhinel) to convey their feelings, latent meanings are often expressed through symbolic metaphors. Viewed in historical perspective, Wang's metaphorical choice of 'cage' and 'birds' appears deliberate. The original user of these metaphorical terms was Chen Yun, a senior economic advisor to Mao Zedong and, during the post-1978 reform era, an opponent of Deng Xiaoping's (relatively) liberal approach to economic governance. Chen argued that the state could not hold 'birds' (i.e. capitalistic actors) tightly in its hands because they would suffocate; yet if the grip on the 'birds' loosened, they would inevitably fly away. The middle ground is to construct a sturdy 'bird cage' (i.e. an economy strongly regulated by the everlasting arms of the CPC) that contains some room for the 'birds' to fly and breathe. Widely-known in China as "birdcage economics" (niaolong jingji), Chen's conceptualization exemplifies the internal logic of the CPC's overall approach to socioeconomic regulation today: the allocation of more "decisive" roles to "the market", the developmental goal proclaimed by 
the Xi Jinping administration at the Third Plenum in November 2013, proceeds in tandem with the reinforcement of state economic involvement (cf. Lin, 2011; Lim, 2014a).

Wang Yang's extension of Chen Yun's metaphor to popularize his province-level restructuring project exemplifies institutional path-dependency in at least two instances. First, it reaffirmed the Four Cardinal Principles instituted by the Deng regime in 1978. These principles are: 1) We must keep to the socialist road; 2) We must uphold the dictatorship of the proletariat; 3) We must uphold the leadership of the Communist Party; 4) We must uphold Marxism-Leninism and Mao Zedong Thought. It is important to note that the third principle is the pivot on which the other three principles rest for full text of Deng's speech on the Four Cardinal Principles, see People's Daily, 30 March 1979). And this principle means the CPC has to determine the territorial parameters for economic 'birds' seeking to maneuver within its inter-scalar rule regime. The economic relations of the Guangdong regulatory regime across and beyond China were thus literally reconfigured through industrial policies like "double relocation" and the designation of "nationally strategic new areas". Yet this proactive approach was still insufficient in itself to guarantee a smooth-sailing state rescaling process. Indeed, as section 4 will show, Wang's restructuring project could materialize only because he had the support of the policymakers at the highest echelon, including the-then Chinese President, $\mathrm{Hu}$ Jintao ${ }^{10}$.

Second, in seeking to retain the economic competitiveness of the PRD through significant industrial reconfiguration, Wang was signaling his intention to stay on the top rung of Deng's 'ladder step' model. As mentioned earlier, this model presumes a 'leveling out' in living standards would occur automatically. Deng's presumption underpinned industrial policies prior to the 2008 "Decisions", and no targeted attempt had been launched to reconfigure the national industrial structure. Wang's subsequent reflections suggest, however, that his fundamental intent in Guangdong was to ensure institutional continuity through change: 
Practice has proven that with the conformity to market rules; with the courage to break through the path dependency that encumbers development; with the elimination of unreasonable interest groups; with the timely increase in developmental quality; and with putting the ability to sustain development in first place, it is definitely possible to create a developmental model that could deliver high value-added products, good quality development and personal income growth that is commensurate with the growth of the economy. (People's Daily, 24 August 2012; author's translation)

Read in relation to his imploration to Dongguan cadres in March 2008, Wang's use of 'market rules' (shichang guilü) to justify breaking out of the labor-intensive, export-oriented "path dependency" (Iujing yilai, the exact equivalent of the term Wang employed) only serves to reinforce the importance of state intervention in enhancing the stability of the national rule regime. As he emphasized during the Dongguan visit, the reconfiguration of spatial divisions of labor could - and should - involve proactive action on the part of local governments (cf. Guangzhou Daily, 27 March 2008). Furthermore, a clause in "Decisions" specified that the restructuring process required a fiscal injection of 50 billion yuan ( US\$7.81 billion) over 5 years. Even with this financial support, there was no guarantee that PRD-based firms - of which a purported 50,000 firms shut down shortly after the crisis - would be willing to relocate to less developed regions within Guangdong province. This essentially means the Guangdong restructuring plan, discursively justified as following 'market rules', was (and remains) an experimental project that entailed the state to underwrite the financial risks. Viewed in relation to state-directed uneven development in China since the Mao era, Wang's approach underscores how the reconfiguration of regulatory relations (still) does not occur because of "market rules". As the next section will elaborate, its occurrence is generated by the "strategic disobedience" that is intrinsic to state rescaling.

\section{The politics of instituting 'double relocation' in Guangdong}

Vis-à-vis the CPC's politico-ideological commitment to spatial egalitarianism, Wang's ambitious approach to shape up and ship out industrial actors within the PRD generated 
two contradictions. At one level, the pursuit of new competitiveness in Guangdong contradicts Deng's previously mentioned vision of attaining similar developmental standards across the country because it perpetuates the coastal bias in development. Central to this vision is the still-binding political commitment to even out income disparities over time. In approving new initiatives to enhance the locational advantage of the Pearl River Delta, however, the Chinese central government was effectively entrenching the geographically-uneven allocation of means of production across China. With reference to the previously-discussed notion of path-dependency, the central government was arguably 'locked in' to its earlier choice to privilege Guangdong in its industrialization policies (ref. section 2). As a third of the national 'floating population' was employed by PRD-based industries, substantial deindustrialization was not politically plausible without first establishing alternative employment opportunities elsewhere in China. While attempts were launched simultaneously through the designation of new growth poles in inland China (primarily through the city-regions of Chengdu. Chongqing, Xi'an-Xianyang and Lanzhou), these attempts arguably represent longer-term solutions to the industrial 'hollowing out' that accompany economic restructuring.

More pressing for national policymakers was the primary injunction to bring in 'upgraded' industries while simultaneously relocating undesirable industries away from the PRD. It must be noted that this injunction in "Decisions" was in itself an experiment: 'emptying the cage' was not only an intra-provincial issue, it would generate direct impacts on national employment. Its overarching objective, as Wang made clear through the People's Daily in October 2008, was to preclude industrial 'hollowing out'. While theoretically sound, it was unclear how the injunction could be put in practice: firms began to shut down, and replacements were hard to find in a period of immense economic uncertainty. Even if higher-order industries were willing to move into the PRD, emerging empirical evidence at the time indicated it would occur only after a time lag. For this 
reason, as will be elaborated shortly, the Chinese central government became concerned with the reconfiguration process. In the midst of economic slowdown, how could the local governments across the province "strongly develop advanced manufacturing industries, high-order advanced technological industries, modern services and equivalent high valueadded industries” (“Decisions”, n.p.; author's translation)?

Within two months of the implementation of "Decisions", there was widespread speculation that the local government in the manufacturing hub of Dongguan had begun 'driving away factories, driving away people' (ganchang ganren). Local cadres purportedly went about 'encouraging' enterprises to relocate. The industrial 'hollowing out' was intensified by two developments, namely 1) the claim of one Dongguan cadre that discussions were underway to halve the city's population [from 12 to 6 million]; and 2) the sudden appearance of extra-provincial officials to entice Dongguan-based firms to leave Guangdong altogether (Interview, planner A, Shenzhen, January 2013). The Dongguan government then came under pressure as worker protests grew (lbid.). These developments impelled Jiang Ling, a CPC cadre and then Vice Mayor of Dongguan, to issue a full-page clarification of the city's restructuring policies in a local newspaper in July 2008 (see Figure 2). Ostensibly a bid to ensure social stability (and indirectly to assure senior leaders in Beijing that economic instability was not occurring at all), the rare occurrence of a CPC cadre publicly defending the state's policies only accentuated the difficulty of attaining simultaneous industrial relocation and upgrading.

\section{Figure 2 here}

The Guangdong government's ambitious reconfiguration of the preexisting spatial division of regulation not only worried local government officials, it raised the concern of national policymakers. Following the announcement of "Decisions", the-then Premier Wen Jiabao made two separate trips to Guangdong in July and November 2008 in an official bid to 'investigate and research' (diaoyan) the economic situation in the province. For a senior 
CPC leader to visit a domestic location for diaoyan twice in one year is rare; to do so twice in 5 months is of political significance. In his July 2008 visit, less than two months after the launch of <Decisions> in Guangdong, Wen opined on his preferred approach to managing the financial crisis:

Guangdong's socio-economy...is confronted with new challenges. The slowdown in the global economy and contraction in external demand has pronounced impacts on exportoriented medium to small enterprises in the PRD. The proportion of non-state linked medium and small enterprises is more developed in Guangdong. Currently these enterprises are faced with more difficulties, hence support must be enhanced through credit, taxation and industrial policies. (China Securities Journal, 21 July 2008; author's translation)

During his second visit and, interestingly, in the company of Wang Yang, Wen Jiabao issued a public reminder that "the problems and difficulties facing medium and small enterprises have not been fundamentally resolved, their production and management situations remain grave. On this, there should be high-level focus and a continuation of initiatives to help these enterprises overcome their difficulties" (People's Daily, 17 November 2008). While appearing conservative and paternalistic, Wen's proposed response was actually predicated on a major principle of governance in China. Contrary to popular conceptions that the CPC prizes GDP growth above all else, any government official in charge of economic development would first be evaluated on his/her ability to maintain social stability before GDP results are evaluated. It was the prospect of social unrest that motivated Wen, the country's top-ranking official in charge of economic development, to adopt a position that placed social stability as the first regulatory priority.

Assessed in retrospect, Wen Jiabao's comments in November 2008 exemplify the inter-scalar tensions involved in reconfiguring the national structure of capital accumulation (cf. section 2). Wen was most likely issuing a targeted, albeit indirect, response to Wang's elaborate view on the issue just a day before his arrival in Guangdong. Made during his visit to the city of Zhanjiang, Wang was defending the Guangdong government's approach to manage medium and small enterprises within the policy framework of 'double 
relocation':

Some people say this year alone [2008] 50,000 firms shut down, whether this figure is true is one matter, everyone should seriously analyze this: amongst those firms that have shut down, how many of them are large-scale firms? None! In my prediction, these [fallen] firms were mostly lagging productive forces. The cyclical extirpation of lagging productive forces is an effect of market economic forces. (Guangzhou Daily, 14 November 2008; author's translation)

Exemplifying a distinctive pattern developed during his tenure in Guangdong, Wang (once again) peppered his explanation in Zhanjiang in relation to "market economic forces", on the premise that the market contained objective rules for governments to follow:

30 years ago, we chose the market economy and consequently enjoyed the joy of fastpaced growth. Today we must also courageously confront the pain brought about by cyclical turbulences in the market. Since the Asian financial crisis in 1997, Guangdong has adopted a particular way to run at high-speed, to slow down a little now, to adjust the style and raise the technical capacities suitable for long distance running, this is very normal...the state should never do what the market will not allow, it should never save lagging productive forces. (lbid.)

Wang's comments were contradictory in two ways, however. First, he reinforced the fact that marketization in post-Mao China was never about the 'free market' or its supposed corollary, perfect competition. By his own admission, the enterprises hurt most by the 'double relocation' policy were medium and small enterprises; "none" of the large-scale firms were hurt or, presumably, were allowed to be hurt. Viewed in itself, the survival of large-scale enterprises (of which it was unclear how many were state-owned) is not surprising, as their production processes were (and remain) largely organized through relatively flexible sub-contractual arrangements with smaller (and largely privately-owned) enterprises. Of greater significance is the Guangdong government's willingness to accept the subservient and vulnerable position of medium and small enterprises - the economic actors that were supposed to be the centerpieces of a 'free market'. This complicates the popular portrayal of Wang as a market-oriented reformer and illustrates the decidedly protectionist undercurrent of the restructuring strategies (cf. Mulvad, 2015). In fact, the intention was not only to ensure the big businesses (in particular those of the SOEs) were shielded from the crisis: it was to provide these businesses with new opportunities for 
capital accumulation in other parts of the province (or, failing which, in other parts of the country).

Second, the sequence of development presented in Wang's comment in Zhanjiang foregrounds how it was the CPC that chose market-oriented governance, not the other way round. The overarching "national strategy", this paper argues, was to enable the CPC to remain in perpetual power (ref. the Four Cardinal Principles). At the policy level, this means having to experiment with new ways of engaging market regulatory logics without compromising the stability of the party-state structure. After the 2008 global financial crisis, the Chinese party-state apparatus again found itself having to choose how to strategically reposition economic geographies across the country. Operating within a context of intensifying global interconnections, however, meant the remaking of state-market relations through state rescaling could not be based on a fixed playbook - the process was proactive, opportunistic and experimental at the same time.

And the inherent risks involved in this multi-dimensional regulatory approach explain why the "nationally strategic" designation of reform frontiers invites "strategic disobedience" (ref. Wedemen, 2001; section 2). Indeed, the Guangdong government's decision to "never save lagging productive forces" and persist in reconfiguring the provincial industrial structure was just as risk-laden as Wen Jiabao's imploration to keep afloat medium and small enterprises through new interventions. Senior policymakers thus had to take a chance on whether the tentative approach in Guangdong would reproduce if not enhance - national economic growth. Just days following Wen's November 2008 visit, Wang offered an oblique counterpoint that reiterated his decision to take this risk:

Amongst these debates, some are for, some against. I thought about it, over the three decades of 'opening up', Guangdong has embarked on its own path, so let others do the debating. Right now it is still the same, we are taking our own path, a path of scientific development, so let others do the debating. Regardless of what others say, the 'double shifts' must be emphasized, 'emptying the cage and changing the birds' must be emphasized. We must never launch just about anything in order to guarantee GDP growth. (Nanfang Dushibao, 21 Nov 2008; author's translation) 
Wang's insistence was the final straw for some senior members of the Politburo. On Christmas day of 2008, the People's Daily published a critical commentary - rarely leveled against senior CPC cadres - to express their views on Wang's restructuring plan:

Just a while ago, medium and small enterprises encountered external and internal difficulties and were effectively immobilized. This especially applied to labor-intensive medium and small enterprises labeled as 'two highs, one low' [high pollution, high energy usage and low efficiency], they were viewed as impediments to industrial upgrading. Some places have appeared too hasty in the process of 'emptying the cage and changing the birds', this caused a significantly squeeze in the survival space for medium and small enterprises. In the face of the strong force brought about by the global financial crisis, the situation of these enterprises has only exacerbated. (People's Daily, 25 December 2008; author's translation)

While not mentioning Wang by name, the intended audience of the message was explicitly stated through the references to Wang's 'emptying the cage to change the birds' metaphor and the industrial classification term of 'two highs, one low' (lianggao yidi):

Even if there are indeed medium and small enterprises that embody the 'two highs, one low', there should not be a simplistic and brutal squeeze of their survival space. Be it in the enhancement of industrial upgrading or in the relocation of these enterprises, policy and financial support must be given. (lbid.)

Following this public opprobrium, Wang's tone softened. "Emptying the cage and changing the birds does not mean emptying out all the birds", Wang explained, "even a fool will not do this" (WenWeiPo, 12 February 2009; author's translation). By implication, the Guangdong restructuring approach was never a 'foolish' one-size-fits-all strategy. Wang further reiterated the stance taken earlier by the Dongguan government:

Even to labor intensive industries and lower-order manufacturing sectors, the 'empty the cage and change the birds' method cannot be based on compulsion. Right now no enterprise is forcibly made to move, no enterprise is having its water or electricity supplies cut, our method is to attract through benefits, we tell enterprises the places where operating costs are low, the places where workers are aplenty, in practice we respect the will of the enterprises, the government uses appropriate policies and hope people make these kinds of choices [i.e. relocate]. (Ibid.)

Yet field research indicates that the Guangdong government's "hope" was officially transposed into a performance target: local officials' ability to successfully implement the 'double relocation' policy could affect their promotional prospects (Interview, Planner C, Shenzhen, January 2013). Interestingly, the formal inclusion of this performance target 
indicates not all officials were supportive of the 'double relocation' policy. After all, as Planner C explains, local village collectives have been highly dependent on rental collection from migrant workers in cities like Dongguan, Jiangmen and Foshan, key manufacturing hubs in the PRD. To push for manufacturing firms and migrant workers to relocate could mean a loss in short-term income if not a local economic contraction, a situation from which Dongguan has yet to fully recover (Ibid.). In other words, a developmental path had been established in industrial hubs like Dongguan, Jiangmen and Foshan that benefited specific interest groups such as village collectives, and naturally these groups resisted change that would compromise their economic interests. Changing paths meant local officials had to turn senior policymakers' "hope" into reality.

At this point, it would be helpful to assess the active involvement of local cadres within the intertwined process of state rescaling, institutional path-dependency and 'strategic disobedience' in China (ref. section 2). While the entire Guangdong economy was in a state of uncertainty during and after 2008, the Wang administration already contemplated economic restructuring independent of the crisis. "Strategic disobedience" was thus in the pipeline; the new ambiguities generated by the financial crisis only catalyzed its actualization. As then-Vice Governor, Zhu Xiaodan, acknowledged, "even without the global financial crisis, it was already time for industrial transformation and upgrading in Guangdong" (Nanfang Dushibao, 8 March 2012). Wang Yang put this point into sharper perspective:

Regarding extra-local relocation, if it occurred during the good times enterprises would be unwilling to move, yet if it occurred during economic contraction some enterprises claim to have no ability to move, then no movement will ever occur. Practically the financial crisis has lowered the costs of relocation, adding to this the government is providing a series of preferential policies to facilitate industrial transformation and upgrading, this moment is an excellent opportunity for [industrial] relocation. (Xinxi Shibao, 18 July 2009; author's translation)

Placed in relation to the post-2007 reconfiguration of regulatory relations in Guangdong, however, Wang's initiative was more accurately a form of strategic alignment with central 
goals. The Guangdong government's apparent "disobedience" was not a lack of "compliance" to an a priori directive from the central government. While the stronglyworded response in People's Daily may be read as a mandate from Beijing to the Guangdong government, the issuance of this directive was actually a response to a bottom-up developmental approach. The cause-effect relation in this process is the direct opposite of Wedeman's (2001) assumption that "strategic disobedience" occurs as a reaction to an a priori directive by the central government.

In addition, there were strong signs the central government had different views on the restructuring process in Guangdong. Under conditions of ambiguity, as the-then Premier, Wen Jiabao, demonstrated in his response to the global financial crisis, the Chinese central government would most likely be cautious in its response. This corresponds to Wedeman's proposition. However, Hu Jintao's subsequent endorsement of the Guangdong project indicates not all policymakers within the central government believed in a cautious response to ambiguities. As it soon became clear, Wang's overt unwillingness to follow Wen's advice led to speculations over differences in the central government's view of Guangdong's 'double relocation' approach. When Hu visited Guangdong in March 2009, Wang said in his presence that "last year [2008], during which our province was confronted by the global financial crisis and was faced with its most difficult moment since the turn of the century, the General Secretary [i.e. Hu] entrusted comrade [Li] Changchun to conduct an investigation of Guangdong and, based on his report, clearly issued opinions that guide our work in Guangdong." (Yangcheng Wanbao, 7 March 2009). There was no mention of Wen's two trips to Guangdong in 2008; Wen's previously mentioned instructions to save medium and small enterprises affected by the global demand slump were also unreferenced. This omission is significant in three ways.

First, it implies Wen Jiabao did not visit Guangdong with Hu Jintao's instructions. Only Li Changchun, another senior cadre in the Politburo, was "entrusted" by the Hu 
government to visit Guangdong. Second, Wang was indirectly saying Wen's comments had no impact on his or Hu's view on industrial policies launched by the Guangdong government. Again, only Li Changchun's report had any impact. And this leads to the third point: the central government's eventual guidance for Guangdong did not include Wen's advice. That Wang could take this daring discursive step strongly suggests he had the full support of the Chinese president in the senior echelons of the CPC. This consequently suggests the central government was unsure of its strategic response to the global financial crisis. To be sure, where differences in opinions existed within the central state apparatus, the proposed restructuring project in Guangdong was not paralyzed. If anything, as Hu put it in his second visit to Guangdong in 2009 , it propelled the project in a forward motion:

In confronting the global financial crisis, the Guangdong government emphasized seizing the favorable circumstance induced by the crisis to reconfigure and enhance the industrial structure and transform the mode of economic development...I think your reasoning is very good, you have to persevere, always move ahead, and truly give a good fight in this tough battle of transforming the economic development approach. To gain awareness early, to act early, is good proactivity. (Guangzhou Daily, 30 December 2009).

Hu's eventual acceptance of the restructuring approach indicates how "disobedience" from lower hierarchical levels is symptomatic of differences within the top echelon of the CPC. Whether its unrelenting stance vis-à-vis calls to help medium and small enterprises would morph into a form of "disobedience" - and hence become subject to what the CPC calls 'party discipline' - was contingent on its ability to capitalize on planning uncertainties with in the central government. More accurately, then, the "strategic" aspect of the Guangdong government's apparent non-compliance lies in how it aligns to and then redefines the 'national interest'. This phenomenon corresponds with Peck's (2002: 340) observation that "the present scalar location of a given regulatory process is neither natural nor inevitable, but instead reflects an outcome of past political conflicts and compromises". In this regard, "strategic disobedience" in Guangdong was not a negative outcome, at least not in the 
short term. What emerged was a delicate operating consensus between different regulatory levels that created new spaces for capital investments and crisis deferral.

\section{Conclusion}

That economic development in Guangdong had been driven by labor-intensive and highlypollutive industries - particularly since the intensification of urban-oriented reforms in the mid-1990s - is well-documented. That this trajectory could not last was also expected. Quite how the province was to undertake structural reforms without undermining its economic importance at the national scale was unknown until the 'double relocation' industrial policy became clear by 2009. The institution of this policy was a politicized process. Viewed in tandem with the Wang administration's high-profile push to 'scale up' Hengqin, Qianhai and Nansha into "nationally strategic" reform frontiers (ref. Figure 1; cf. Lim, 2014a), the 'double relocation' strategy may not appear to be directly of the 'national interest'. On closer inspection, however, this industrial policy was a means to enable the institution of new reforms and policy experimentation in Guangdong. In other words, the emergence of new regulatory logics in Guangdong entailed a shift in its underlying industrial structure, a prerequisite that would not be met without the proactive intervention of Guangdong policymakers. This paper is a critical evaluation of this intervention.

Two conceptual implications can be drawn from the state rescaling process in/of Guangdong. On the one hand, Hu's decision reflects the growing importance of bottom-up governance: the Guangdong government successfully pushed through its restructuring agenda and 'won'. Perhaps more significantly, the crisis offered an opportune moment for the Guangdong policymakers to create new "nationally strategic" opportunities as part of the restructuring project: while the large-scale shutdown of medium and small enterprises may constitute an excruciating short-term blow to employment and income, the Guangdong policymakers simultaneously sought to ease the economic pain by imploring 
the central government to designate the territories of Hengqin, Qianhai and Nansha as "nationally strategic" reform frontiers (ref. locations in Figure 1). This active engagement with the central government complicates simple models that view centralization and decentralization as a binary. It calls, instead, for a systematic evaluation of industrial restructuring in the PRD - multiple policies in different locations were instituted simultaneously between 2008 and 2012, each engaging with different inherited institutions, each generating new relations with the central government and transnational capital.

On the other hand, the persistence of a fragmented national economy is not engendering a resurgence of autonomous 'feudal economies' (zhuhou jingji). Rather, it demonstrates how the system of reciprocal accountability, to re-borrow Shirk's (1993) terms, has generated immense political and economic incentives for the alignment of local developmental agendas to the centrally-determined "national strategy" (ref. section 2). This in turn calls for the relationship between Wang Yang and senior policymakers like $\mathrm{Hu}$ Jintao and Wen Jiabao to be evaluated at the macro-structural level. Despite their differences, all three were embedded within the system of reciprocal accountability and were expected to behave strategically within the logics of this system. For the Wang administration, the strategic objective was to ensure the PRD city-region (and Guangdong more broadly) remain attractive to capital. Its practical goal was to assure both the central government and corporate investors that the province remains an attractive site of/for capital accumulation.

With the provincial economy increasingly impacted by the 2008 global financial crisis (and which, at the time, showed no signs of abating), Wang made a drastic announcement to categorize redundant economic actors as "lagging productive forces". The outcome was a form of managed deindustrialization. According to official figures revealed by the Zhu Xiaodan, the Governor of Guangdong, more than 7000 firms were relocated (though it was not known whether they relocated within the province or moved to 
other regions within China) between 2008 and 2012, while a staggering total of almost 80000 firms either stopped operations or shut down during the same period (WenWeiPo, 26 January 2013). Against these signs of economic contraction, the Guangdong government enabled GDP and employment growth in Guangdong to remain positive throughout the post-crisis period (i.e. 2009 to the present). This achievement has to be assessed in relation to the previously mentioned "nationally strategic new areas" in the PRD and industry-specific upgrading in the PRD (cf. Chen and Ku, 2014).

Place within a broader geographical-historical context, the 'double relocation' policy in Guangdong indicates state rescaling in China is not an end-state that can be attained or secured. It is not a mechanical, one-way devolution of regulatory capacities from the national scale to the supra- or sub-national governments. To demonstrate this, this paper moved beyond an uncritical mapping of state rescaling to explain how the reconfiguration of regulatory scales functions as an ongoing process of contestation, negotiation and comanagement of state space. In so doing, it foregrounded the contradictions associated with national-scale regulatory directives, some launched back in the 1950s (cf. Peck and Zhang, 2013; Zhang and Peck, 2015). Specifically, the post-crisis restructuring agenda in Guangdong reaffirmed the difficulty - if not impossibility - of attaining Mao and Deng's joint vision of national spatial egalitarianism. The central government's willingness to approve this agenda (which has since been emulated by other coastal city-regions in Zhejiang and Jiangsu) further undermines attempts by the Jiang Zemin and $\mathrm{Hu}$ Jintao administrations to institute more 'coordinated' regional development (quyu xietiao fazhan). These contradictions collectively underscore the difficulty of actualizing Pareto-optimality in interregional resource transfers within the context of intensifying global economic integration. Indeed, insofar as place-specific competitiveness in the global economy remains a core policy concern for the CPC, it appears that new rounds of policy experimentation and reforms in China will continue to be shaped by the tensions between rescaling initiatives, 
each with its own set of 'strategic disobedience', and the tendency, if not temptation, to traipse along the developmental pathways instituted by earlier regimes.

\section{Notes}

1 The socioeconomic statistics - including GDP - of Hong Kong and Macau are calculated separately from mainland China.

2 It is not within the scope of this paper to discuss the emergence of these territories known officially as "nationally strategic new areas". In summary, Wang pushed for the designation of these territories as delimited zones of policy experimentation. The policies are to be of significance to both the Chinese central government and the economies of Macau and Hong Kong SARs. A key point to be made in this paper is the constitutive role of the 'double relocation' policy in the designation of these three territories. For an overview of the broader significance of spatially-targeted experimentation in these 'new areas', see Lim (2014).

${ }^{3}$ Officially, given the lack of inter-provincial coordination, it has to be stated that relocation policies remain within the province so that the government appears to prioritize the provincial interests. This is an extension of the protectionist, inward-looking tendencies of the Mao era. In reality, however, given the huge difference in infrastructural facilities between the PRD and the rest of Guangdong province, the Guangdong government in fact did not mind if undesirable industries leave the province altogether rather than attempt to upgrade these industries within the province (Interview, academic and regular consultant to the government, January 2013).

4 The empirical materials presented in this paper draws from fieldwork conducted between February 2012 and January 2013 on a broader, multi-sited project on policy experimentation and the shifting logics of socioeconomic regulation across China. Discursive materials from key political actors were sourced and translated by the author; supporting materials were drawn from direct interviews with CPC cadres, planners and scholars in several cities in the Pearl River Delta. Often on the advice of these interviewees, further follow up work was done to derive supporting evidence. The field research was supplemented by archival work conducted in Beijing, Shenzhen and Chongqing. The materials were then triangulated to align to the analytical approach, which is similar to what Zhang (2012: 2855) terms "a social constructivist approach" that "brings to the foreground the constitutive socio-spatial context or unique historical-geographical conjuncture of policy-making activities". Adopting this approach entails juxtaposing a range of information to present a multi-perspectival narrative on the connections between state rescaling and institutional path-dependency.

${ }^{5}$ This, incidentally, is the rationale for the 'shock therapy' approach to reforms in the former Soviet bloc, i.e. to incapacitate defenders of the old regime. Geographically-targeted policy experimentation is an alternative approach to "managed" transformation in which everything changes at once.

${ }^{6}$ Ratios for both Guangdong and China determined by author's calculation.

7 The official term of this transformation project in Mandarin is <珠江三角洲地區改革發展規劃綱要 $2008-2020$ 年>. The cited content is printed on page 7 of the original document; translated by author.

8 This term that would subsequently be widely used to characterize Guangdong's province-wide restructuring approach.

${ }^{9}$ The official term of this policy in Mandarin is <關於推進產業轉移和勞動力轉移的決定>.

${ }^{10} \mathrm{Hu}$ 's support was important at both the personal level and in terms of national economicgeographical reconfiguration. In 2007, when Wang was Party Secretary of Chongqing, Hu approved a series of nationally-strategic socioeconomic policies aimed at bridging the urban-rural divide caused by the Mao-era household-registration (or hukou) institution of population control. That Hu would approve these major reforms during Wang Yang's term was a glowing recognition of the latter's efforts at initiating institutional reforms. Ironically, it was precisely the institution Wang tried to reform in Chongqing - the hukou system - that enabled the Guangdong government to effect labor force relocation at will (ref. Lim, 2014b; Mulvad, 2015). 


\section{References}

$21^{\text {st }}$ Century Business Herald (2015) Liudong renkou diaocha: Anhui liuchu renkou zuiduo, Guangdong liuru zuiduo [Investigation on floating population: Anhui has largest outflow and Guangdong largest inflow]. 11 April.

Bai, C. E., Du, Y., Tao, Z., \& Tong, S. Y. (2004). Local protectionism and regional specialization: evidence from China's industries. Journal of International Economics, 63(2), 397-417.

Bayirbağ, M. K. (2013). Continuity and change in public policy: redistribution, exclusion and state rescaling in Turkey. International Journal of Urban and Regional Research, 37(4): 1123-1146.

Brenner, N. (2004) New State Spaces. Oxford: Oxford University Press

Breslin, S. (2007) "The Political Economy of Development in China: Political Agendas and Economic Realities", Development, 50(3): 3-10.

Cartier, C. (2005) City-space: scale relations and China's spatial administrative hierarchy. In Ma, L. J. C. and Wu, F. (eds.) Restructuring the Chinese City: Changing Society, Economy and Space, pp. 21-38. Abingdon: Routledge.

Chen, T. J., and Ku, Y. H. (2014). Indigenous innovation vs. teng-long huan-niao: policy conflicts in the development of China's flat panel industry. Industrial and Corporate Change 23 (6): 1445-1467.

China Securities Journal (2008) "Wen Jiabao zai Guangdong diaoyan, qiangdiao jiada zhichi zhongxiao qiye lidu", 21 July.

Chien, S. S. (2010). Economic freedom and political control in post-Mao China: A perspective of upward accountability and asymmetric decentralization. Asian Journal of Political Science 18(1): 69-89.

Demurger, S., D Sachs, J., Woo, W. T., Shuming, B. A. O., \& Chang, G. (2002). The relative contributions of location and preferential policies in China's regional development: being in the right place and having the right incentives. China Economic Review, 13(4), 444-465.

Deng, G. and Kennedy, S. (2010). Big business and industry association lobbying in China: The paradox of contrasting styles. The China Journal, 101-125.

Donnithorne, A. (1972) China's Cellular Economy: Some Economic Trends since the Cultural Revolution. The China Quarterly 52: 605-619.

Ferchen, M. (2013). Whose China Model is it anyway? The contentious search for consensus. Review of International Political Economy, 20(2): 390-420. 
Göbel, C. (2011). Uneven Policy Implementation in Rural China. The China Journal, 53-76.

Guangzhou Daily (2008) “Jintian bu jiji tiaozheng chanye jiegou, mingtian jiuyao bei chanye jiegou tiaozheng”, 27 March.

Guangzhou Daily (2008) "Wang Yang: Miandui jingji kunnan yao you xinxin, zhengfu bujiu luohou shengchanli”, 14 November.

Guo, W. and Feng, Y. (2009) Cost Impact and Industrial Upgrading in Pearl River Delta Region: Case Study on Shenzhen and Dongguan. In Saw S.-H. and John Wong (eds.) Regional Economic Development in China. Singapore: Institute of Southeast Asian Studies, pp. 53-78.

Harding, H. (1981). Organizing China: the Problem of Bureaucracy, 1949-1976. Stanford: Stanford University Press.

Harrison, J. (2010) Networks of connectivity, territorial fragmentation, uneven development: The new politics of city-regionalism. Political Geography, 29(1): 17-27.

Heilmann, S. and Perry, E. (eds)(2011) Mao's Invisible Hand: The Political Foundations of Adaptive Governance in China. Cambridge, MA: Harvard University Press.

Horowitz, S. and Marsh, C. (2002). Explaining regional economic policies in China: interest groups, institutions, and identities. Communist and Post-Communist Studies, 35(2), 115132.

Huang, Y. (2008) Capitalism with Chinese Characteristics: Entrepreneurship and the State. Cambridge: Cambridge University Press.

Ke, Q. (1959) Lun 'Quanguo yipanqi' [On 'the nation as a chessboard']. Hongqi, 4: 9-12.

$\mathrm{Li}, \mathrm{Y}$. and Wu, F. (2012). The transformation of regional governance in China: The rescaling of statehood. Progress in Planning, 78(2): 55-99.

Liang, Z., Li, Z., and Ma, Z. (2014). Changing Patterns of the Floating Population in China, 2000-2010. Population and Development Review, 40(4): 695-716.

Lim, K. F. (2014a). 'Socialism with Chinese characteristics': Uneven development, variegated neoliberalization and the dialectical differentiation of state spatiality. Progress in Human Geography, 38(2): 221-247.

Lim, K. F. (2014b). Spatial egalitarianism as a social 'counter-movement': on socioeconomic reforms in Chongqing. Economy and Society, 43(3), 455-493.

Lin, G. C. S. (1997) Red capitalism in South China: Growth and Development of the Pearl River Delta. Vancouver: UBC Press.

Lin, S. (2003) Dalu jingji jiegou tiaozheng zhanlüe [Economic restructuring strategy of mainland China]. Beijing: Zhongguo Shehui Kexue Chubanshe. 
Lü, X. (2000). Cadres and corruption: The organizational involution of the Chinese communist party. Stanford: Stanford University Press.

Ma, L. J. (2005). Urban administrative restructuring, changing scale relations and local economic development in China. Political Geography, 24(4): 477-497.

Mao, Y. (2013) Zhongguoren de jiaolü cong nalilai [Where are the Chinese people's worries from?]. Beijing: Qunyan Press.

Martin, R. and Sunley, P. (2006). Path dependence and regional economic evolution. Journal of Economic Geography, 6(4), 395-437.

Martin, R. (2010). Roepke Lecture in Economic Geography-Rethinking Regional Path Dependence: Beyond Lock- in to Evolution. Economic geography, 86(1), 1-27.

Massey, D. (1984[1995]) Spatial Divisions of Labour. London: Routledge.

McGregor, R. (2012). The Party: The Secret World of China's Communist Rulers. (Revised edition). London: Penguin.

Mulvad, A. (2015). Competing Hegemonic Projects within China's Variegated Capitalism: 'Liberal' Guangdong vs. 'Statist' Chongqing. New Political Economy, 20(2), 199-227.

Nanfang Dushibao (2008) "Wang Yang huiying 'bujiu luohou shengchanli': zou ziji delu, rang bieren yilun quba" 21 November.

Nanfang Dushibao (2012) "Zhu Xiaodan lianghui toulu Hu Jintao zhan Guangdong zhuanxing 'renshi qingxing'", 8 March.

Nanfang Dushibao (2012) Guangdong sannian liangdu 'daobichao' [2 waves of closures in Guangdong within 3 years]. 2 April.

Nanfang Ribao (2013) Guangzhu chenggui yanchangxian niandi youwang kaigong [Guangzhou-Zhuhai railway line could begin work at year-end]. 7 November.

Naughton, B. (1995) Growing Out of the Plan: Chinese Economic Reform, 1978-1993 Cambridge: Cambridge University Press.

Naughton, B. (2008) “A political economy of China's economic transition”. In China's Great Economic Transformation. Brandt \& Rawski (eds.), Cambridge University Press, Cambridge, pp. 91-135.

Page, S. E. (2006) Path dependence. Quarterly Journal of Political Science, 1: 87-115.

Pearson, M. M. (1994). The Janus face of business associations in China: Socialist corporatism in foreign enterprises. The Australian Journal of Chinese Affairs, 31: 25-46.

Peck, J. (1998). Geographies of governance: TECs and the neo-liberalisation of 'local interests'. Space \& Polity, 2(1): 5-31. 
Peck, J. (2002). Political Economies of Scale: Fast Policy, Interscalar Relations, and Neoliberal Workfare. Economic Geography 78(3): 331-360.

Peck, J. (2003). Geography and public policy: mapping the penal state. Progress in Human Geography, 27(2), 222-232.

Peck, J., and Zhang, J. (2013). A variety of capitalism... with Chinese characteristics?. Journal of Economic Geography, 13(3), 357-396.

People's Daily (1959) Shelun: Quanguo yipanqi. [Editorial: The nation as a chessboard]. 24 February.

People's Daily (2008) Wang Yang: Zhusanjiao yao shixian tenglong huanniao [PRD must attain 'empty the cage and change the birds']. 17 October.

People's Daily (2008) Renmin Ribao Jingji Shiping: Kuoda jiuye shandai zhongxiao qiye [People's Daily editorial: Expand employment and treat small and medium enterprises benevolently]. 25 December.

People’s Daily (2009) Guangdong's foreign trade and FDI improve in H1. 3 August.

Peters, B. G., Pierre, J. and King, D. S. (2005) The Politics of Path Dependency: Political Conflict in Historical Institutionalism. The Journal of Politics 67(4): 1275-1300.

Rawski, T. G. (1995). Implications of China's Reform Experience. The China Quarterly, $144,1150-1173$.

Rhodes, R.A.W. (1997) Understanding Governance. Buckingham and Philadelphia: Open University Press.

Shen, J. (2007) "Scale, state and the city: Urban transformation in post-reform China." Habitat International 31.3 (2007): 303-316.

Sheng, Y. (2007). Governing Economic Openness: Provincial Level Evidence from China (1972-2002). Comparative Political Studies, 40(4): 405-34.

Shirk, S. L. (1993) The Political Logic of Economic Reform in China. Berkeley: University of California Press.

Smart, A., \& Lin, G. (2007). Local capitalisms, local citizenship and translocality: rescaling from below in the Pearl River Delta region, China. International Journal of Urban and Regional Research 31(2): 280-302.

Su, X. (2012) Rescaling the Chinese state and regionalization in the Great Mekong Subregion. Review of International Political Economy 19(3): 501-527.

Topal, A. (2015). Global Processes and Local Consequences of Decentralization: A Subnational Comparison in Mexico. Regional Studies 49(7): 1126-1139. 
Wang, S. and Hu, A. (1999). The political economy of uneven development: The case of China. ME Sharpe.

Wang, Y. P., Wang, Y. and Wu, J. (2009). Urbanization and informal development in China: urban villages in Shenzhen. International Journal of Urban and Regional Research, 33(4), 957-973.

Wedeman, A. (2001). Incompetence, noise, and fear in central-local relations in China. Studies in Comparative International Development 35(4): 59-83.

Wei, Y. D. and Liao, F. H. (2013). The embeddedness of transnational corporations in Chinese cities: Strategic coupling in global production networks?. Habitat International, 40, 82-90.

Wenweipo (2009) Wang Yang gaikou: Tenglong huanniao zhishi daoxiang, bu qiangzhi qiye zhuanyi [Wang Yang's change of words: empyting the cage is only a guidance, firms not compelled to relocate]. 12 February.

Wenweipo (2013) Wunian tenglong huanniao, yue 8 wan qiye guanting. [5 years of emptying the cage and changing the birds, 80000 enterprises shut down]. 26 January.

Wu, F. (2015) Planning for Growth: Urban and Regional Planning in China. New York: Routledge.

Xia, Y. and Feng, Z. (1982) Tidu lilun yu quyu jingji [Ladder-step theory and regional economies]. Shanghai Kexue Yanjiusuo Qikan (Yanjiu yu jianyi), 8: 21-24.

Xinxi Shibao (2009) "Wang Yang jingcai yulu”, 18 July.

Xu, C. (2011) The fundamental institutions of China's reforms and development. Journal of Economic Literature 49: 1076-1151.

Yang, C. (2012). Restructuring the export-oriented industrialization in the Pearl River Delta, China: Institutional evolution and emerging tension. Applied Geography 32(1): 143-157.

Yu, H. (2014a). China's "Ghost Cities". East Asian Policy, 6(02): 33-43.

$\mathrm{Yu}, \mathrm{H}$. (2014b). The Ascendency of State-owned Enterprises in China: development, controversy and problems. Journal of Contemporary China, 23(85): 161-182.

Zhang, J. (2012). From Hong Kong's capitalist fundamentals to Singapore's authoritarian governance: the policy mobility of neo-liberalising Shenzhen, China. Urban Studies, 49(13), 2853-2871.

Zhang, J. (2013). Marketization beyond neoliberalization: a neo-Polanyian perspective on China's transition to a market economy. Environment and Planning A, 45(7), 1605-1624.

Zhang, J. and Peck, J. (2015). Variegated Capitalism, Chinese Style: Regional Models, Multi-scalar Constructions. Regional Studies, 50(1), 52-78. 
Zheng, S., Long, F., Fan, C. C. and Gu, Y. (2009). Urban villages in China: A 2008 survey of migrant settlements in Beijing. Eurasian Geography and Economics, 50(4), 425-446.

Zhu, H. (2004) Zhongguo quyu jingji fazhan zhanlüe [Regional economic development strategy of China]. Beijing: Shehui Kexue Wenxian Chubanshe. 